\title{
Older assistant nurses' motivation for a full or extended working life
}

\author{
Kristina Gyllensten ${ }^{1 *}$, Kerstin Wentz ${ }^{1}$, Carita Håkansson ${ }^{2}$, Mats Hagberg ${ }^{1}$ and Kerstin Nilsson ${ }^{2}$ \\ ${ }^{1}$ Department of Occupational and Environmental Medicine, University of Gothenburg and Sahlgrenska \\ University Hospital, Gothenburg, Sweden and ${ }^{2}$ Division of Occupational and Environmental Medicine, \\ Lund University, Lund, Sweden \\ ${ }^{*}$ Corresponding author. Email: kristina.gyllensten@amm.gu.se
}

(Accepted 30 May 2018; first published online 16 July 2018)

\begin{abstract}
The aim of this study was to explore older workers' motivation for a full or extended working life. With particular focus on assistant nurses aged 55-64 years, working in the elderly care sector. Focus group interviews were conducted with five different groups of assistant nurses. Inductive thematic analysis was used to analyse the interviews and five main themes were developed from the data: 'Organisational issues', 'Health-related problems', 'Private issues', 'Meaningfulness and appreciation' and 'Social support'. Several of the main themes concerned problems with too high work demands of the assistant nurses. These findings suggest that it is important to improve the working conditions of assistant nurses in order to create a more sustainable working life. Increasing the number of staff and improving recovery opportunities and work-life balance could be important steps to improving the working conditions for this group. Finally, upgrading the competency and professionalism of assistant nurses could help to increase the motivation for a full or extended working life.
\end{abstract}

Keywords: elderly care; older workers; qualitative research; retirement; working conditions

\section{Introduction}

The workforce in Europe is getting older than ever before (Organisation for Economic Co-operation and Development 2007). State pension ages (SPA) have been raised in many European countries (Round 2017) and the European Union supports retirement reforms that encourage and enable people to work longer (European Commission 2012). In the United Kingdom, for example, the SPA will rise to 66 by the year 2020 and further increases are planned (Lain and Vickerstaff 2014). This demographic shift poses both challenges and opportunities and calls for the implementation of policies that promote healthy ageing and a sustainable working life (Nilsson 2016a). One sector that will be greatly affected by these demographic changes is the elderly care sector. There will be an increased

(c) Cambridge University Press 2018. This is an Open Access article, distributed under the terms of the Creative Commons Attribution licence (http://creativecommons.org/licenses/by/4.0/), which permits unrestricted re-use, distribution, and reproduction in any medium, provided the original work is properly cited. 
need for staff working in elderly care (Sandmark 2014). For a number of years elderly care in the Nordic countries has focused on reducing costs and attaining greater efficiency, which has caused concern for the wellbeing of the care staff (Elstad and Vabø 2008).

A study investigated working conditions and recovery, among staff working in elderly care, and found that difficult working conditions were associated with a high need for recovery and impaired self-rated health (Aronsson, Astvik and Gustafsson 2013). Another study, with assistant nurses and nurses, found that high job demands were related to less personal accomplishment, more exhaustion and depersonalisation. Job resources such as opportunity for nurturing, reassurance of worth and support from supervisors, friends or family members were associated with higher levels of personal accomplishment and less emotional exhaustion (Woodhead, Northrop and Edelstein 2016). In addition, it has been found that nursing facilities with a low turnover have more of a culture of respecting nursing assistants compared to facilities with a high turnover (Noelker et al. 2006). For those working in the health-care sector, the conflict between work and personal life has been found to be a major contributing factor in work stress (Munir et al. 2012). Moreover, work-life conflict has been related to a number of negative outcomes, including burnout, depression, low job satisfaction and low psychological wellbeing. These outcomes have, in turn, been related to intention to leave the health-care profession, sickness absence and poor work performance (Munir et al. 2012).

A number of studies have examined older workers plans for retirement and an extended working life within the health-care sector (Bengtsson and Nilsson 2004; Nilsson 2006, 2015, 2016a, 2016b, 2017a, 2017b; Nilsson and Nilsson 2017a, $2017 b$; Nilsson, Rignell-Hydbom and Rylander 2011, 2016). It was found that perceived health was the most important factor in the decision on when to retire. Other important factors included societal norms about working and pension, economical incentives, physical and psychological working conditions, attitudes at the workplace, work satisfaction, social relationships at work, and home and family life. It was concluded that it is important to address these factors in the working environment in order to increase the workers' ability to maintain an extended working life (Nilsson 2012, 2016a, 2016b, 2017c, 2017d; Nilsson, Rignell-Hydbom and Rylander 2011, 2016; Nilsson et al. 2016). A qualitative study investigated plans for retirement among older assistant nurses working in elderly care (Sandmark 2014). The job was viewed as meaningful and important but the participants were unsure if they would manage and have the strength to work until 65 years of age.

The elderly care sector will be increasingly strained in the future. Therefore, investigating older assistant nurses' motivation for a full or extended working life (65 years is the normative retirement age in Sweden) can play an important part in understanding and developing a sustainable working life.

\section{Aim}

The aim of this study was to explore older workers' motivation for a full or extended working life, with particular focus on assistant nurses working in the elderly care sector. 


\section{Method}

This study was made in collaboration between the University of Lund and the University of Gothenburg and was part of a larger research project, 'Enabling participation, health and well-being of ageing workers: towards a sustainable and inclusive working life'.

\section{Procedure}

Focus group interviews were used to collect the data, and this method can be particularly useful when exploring individuals' experiences or knowledge within a specific area, including health and medicine. As a method, focus groups take advantage of the communication between the participants in the group. Consensus or dissent can be used to explore values, and the complexity of motives and behaviours can be investigated, as the participants can compare their experiences and opinions (Kitzinger 1995). Each focus group interview started with an introduction of the participants, and the group members were encouraged to exchange experiences, discuss with each other and comment on each other's contributions. The interviews explored the topic of motivation for extended work life in elderly employees, and the interview schedule contained open questions relating to work, retirement, extended work life, psycho-social work characteristics, work-family conflict and health. The interviews were led by one or two interviewers, then tape recorded and transcribed verbatim. Each interview took approximately two hours.

\section{Data analysis}

Inductive thematic analysis (Braun and Clarke 2006) was used to analyse the interviews, as this is a flexible approach that can provide a rich, detailed and complex account of the data. It was assumed that the investigation of motivation and work-life balance in elderly employees could result in different themes rather than being explained by one single phenomenon. Therefore, inductive thematic analysis, a flexible approach that could present several different themes grounded in the data, was deemed useful. In the first step, the transcribed interviews were coded line by line separately by two of the authors (K.G. and K.N.). From the initial codes more abstract preliminary themes were created for each interview. These themes were reviewed, defined and named within the analytic process. The authors did the initial list of themes separately, and compared and reviewed the themes together in a collaborative spirit acknowledging the richness in the data.

\section{Participants}

The participants selected to the study had to work in municipal health and elderly care homes. Six focus groups were arranged to collect the data. Each group consisted of four to eight participants, and each group met on one occasion. The focus groups in western Sweden were randomly selected by Statistics Sweden from among those registered as working as assistant nurses in Gothenburg and being born between the years 1951 and 1960. On the basis of this selection, the researchers contacted 399 individuals by letter, inviting them to participate in a 
group interview on the topic of motivation and work-life balance. The informants in the focus groups in southern Sweden were recruited via announcement by Kommunförbunet Skåne (Skåne Association of Local Authorities). The association includes 33 municipal authorities. The inclusion criteria were working as an assistant nurse in municipal health and elderly care, and being born between the years 1951 and 1960. Only two municipal health and elderly care organisations were interested in participating. The managers in those two organisations presented their employees with the opportunity to participate and selected the participants. Two focus group interviews were performed, one in each municipality. Each focus group interview started with an introduction of the participants. However, during the introduction, it was revealed that two participants were working in the home care service. Because those two participants did not fulfil the inclusion criteria (working at a care home), this focus group interview was not included in the final analysis. Finally, 27 assistant nurses participated in the analysed group interviews, 26 women and one man, aged between 55 and 64 years.

\section{Results}

The inductive thematic analysis resulted in identification of five themes and a number of sub-themes (see Table 1).

\section{Organisational issues}

The work situation was described as physically and mentally demanding, with too many work tasks, lack of staff, and insufficient recovery during and between the shifts. These work conditions had negative effects both for the staff and the patients, and affected retirement plans.

\subsection{High demands}

Participants reported that they did their best to carry out the various work tasks, but that it was difficult to complete them all in the time available. The pressing work situation created an unsustainable work situation and affected participants' motivation and willingness to stay at work. Indeed, the high demands resulted in a longing for retirement.

There is less staff, cutbacks and more demands. And there are many different tasks that we have to do, and we don't do enough, and then you feel bad, and when you feel bad you would like to retire early. That is the way it is. (Western Sweden, 4: 1051-1053) ${ }^{1}$

It is burdensome to work at a care home for the elderly. It is very heavy work. So I look forward to retirement. I will leave with joy. (Western Sweden, 3: 142-147)

Today they run down the staff ... instead of taking care of us. (Western Sweden, 1: 273-275)

One way of handling the pressing work situation with too many tasks was to increase the work pace. 
Table 1. Main themes and sub-themes

\begin{tabular}{|ll}
\hline Main themes & \multicolumn{1}{c}{ Sub-themes } \\
\hline 1. Organisational issues & $\begin{array}{l}\text { 1.1. High demands } \\
\text { 1.2. Lack of staff } \\
\text { 1.3. Lack of recovery at work }\end{array}$ \\
\hline 2. Health-related problems & $\begin{array}{l}\text { 2.1. Tiredness and aches } \\
\text { 2.2. Individually created solutions to cope with chronic } \\
\text { health problems }\end{array}$ \\
\hline 3. Private issues & $\begin{array}{l}\text { 3.1. Poor personal finances postpone retirement } \\
\text { 3.2 Lack of private life }\end{array}$ \\
\hline 4. Meaningfulness and & $\begin{array}{l}\text { 4.1. Meaningful job } \\
\text { appreciation }\end{array}$ \\
\hline 4.2. Downgrading of competencies \\
\hline 5ocial support
\end{tabular}

Everyone ends up trying to run a little bit faster in order to do the things that need to be done. And then it goes unnoticed; nobody notices it. (Western Sweden, 2: 638-639)

\subsection{Lack of staff}

There was a lack of staff at the nursing homes, according to the participants, and hiring more staff was a solution that was repeatedly put forward. Recruiting more staff would bring the energy and the joy back to the work, according to the participants.

If you feel unwell, you can get backache, you can get symptoms, but really it is your situation that is wrong ... I think it is the work situation. Once again, hire more staff, really everything will be solved. Maybe not straight away, but it will be solved and everyone will feel better. (Western Sweden, 1: 1574-1579)

The lack off staff had negative consequences for the patients as well as for the staff.

The awful truth is that it is not only we that suffer because of the lack of staff - the patients suffer as well. (Western Sweden, 3: 427-428)

\subsection{Lack of recovery at work}

Coffee breaks had been eliminated in many places and opportunities for short breaks or pauses during the work shifts were lacking. Thus, there was an insufficient time for recovery during the working day. 
The coffee breaks are now completely gone. (Western Sweden, 1: 872)

If I ask everyone here, all of us staff, how many take regular breaks, there are not many that will raise their hands. (Western Sweden, 2: 433-435)

Sometimes it was possible to take breaks during the shifts, but these were often interrupted.

There is no given coffee break. You can take the break when you have the time, and most of the time you don't finish that cup of coffee because there is an alarm going off, or something similar ... but we don't have a break. (Western Sweden, 3: 1038-1039)

\section{Health-related problems}

Health-related issues such as tiredness and lack of energy marked working life for the assistant nurses participating in the study. Moreover, the work situation was not well adapted to chronic health problems, so the participants who suffered from chronic illness created their own solutions to be able to continue working.

\subsection{Tiredness and aches}

Many participants described their ongoing feelings of tiredness and a lack of energy as having a negative effect on their ability to continue to work in older age. Despite liking the work, the lack of energy made it difficult to continue.

I like it a lot, to work where I am working. And it is difficult to imagine that I won't belong in a couple of years' time ... but I feel that I don't have the energy. (Western Sweden, 2: 921-922)

Health issues, such as aches and feeling worn down, were factors that made the participants consider retirement.

It is not long ago [that I took the decision to retire at 63]. It is not, but I feel that I will not be able to cope. I have a lot of ache, and that is the worst part. (Western Sweden, 2: 916-917)

Some participants planned to leave working life before the holiday period to escape that physical demanding working period.

I have a lot of pain in a knee because I am worn out. I am just beat and waiting for the orthopaedic for it. However, I am going to leave working life. I'm 65 the first of April. I want to leave working life at the end of June. Before the holiday. I cannot work another summer with temporary workers. Even if I only work part-time (50\%). It's too physically heavy. Yes, it's really heavy. (Southern Sweden, 2: 1087-1091)

\subsection{Individually created solutions to cope with chronic health problems}

Chronic health issues were part of life for several participants, and they expressed that they had to develop their own individual ways of dealing with these to be able 
to work. The workplaces were reluctant to adapt the working situation to make it easier to work with a chronic illness.

I was seriously ill and I didn't get any help ... I had many setbacks, and that is why I decided to work part-time ... I don't want to deal with Försäkringskassan [Swedish Social Insurance Agency] that only makes you feel worse. So it is better that you sort your own life. (Western Sweden, 1: 1540-1544)

There appeared to be a lack of support and understanding of chronic health issues from the managers' side and expectations that elderly workers be healthy.

She said that if you come to work we expect you to be healthy. Who among us in our sixties is completely healthy? (Western Sweden, 1: 1559-1560)

However, some managers were more understanding towards chronic health problems and could adapt the work schedule, whereas others did not.

I didn't have to work weekends in the end, because sometimes I had to take holiday days in order to cope. And then my manager said, 'No, you should not have to do that.' So I didn't have to do that until a year ago, when we got a new manager: 'I can't treat you any different from the rest.' But I said that I am working part-time because of health reasons. But she said that it didn't matter. (Western Sweden, 2: 965-970)

\section{Private issues}

Poor personal finances and a lack of private life were negative aspects of working as an assistant nurse. These aspects had an effect on the participants' thoughts regarding retirement.

\subsection{Poor personal finances postpone retirement}

The personal finances of the assistant nurses played an important role in the retirement decision. Generally, they said that they had a low income and that their pension was going to be low. In order to receive a higher pension, some participants were planning to continue working.

We will work longer, mainly because of the money. (Southern Sweden, 5: 77-78)

Working part-time at the same time as collecting the pension was one way to improve the financial situation.

The actual pension is a catastrophe ... I am therefore planning to work one, two days extra, so that I will be OK financially ... [living on] only the pension is not possible. (Western Sweden, 4: 1575-1579)

The level of the pensions was discussed among the participants, and they regarded their pensions as very low. 
This pension is a catastrophe. (Western Sweden, 4: 1587)

\subsection{Lack of private life}

There was a lack of private life because much of the spare time was used to recover from work. According to the participants, their work situation had a negative effect on their relationships with friends and family in several ways. The work schedule, particularly working every other weekend, made it difficult to find time to meet family and friends.

I have lost two-thirds of my friends. They know there is no point calling her and asking if she wants to come to this or the other, because she can't, she works all the time. Because I often work when they are off ... Christmas, I am working all during the Christmas weekend. (Western Sweden, 2: 1202-1205)

I don't have a private life. (Western Sweden, 2: 944)

Working weekends appeared to have a very negative effect on the participants' social life.

I work every other weekend. I work four days, then I am off for one day, work four days and then every other weekend off. Way too little recovery. I got a telling-off from my brother last summer; he said that I never call and never come to visit. I said that I don't have the energy. After work I go home, cook, eat, sit on the couch and then I go to bed. (Western Sweden, 3: 980-983)

For one participant, working every other weekend made it difficult to spend time in the family's summer house.

I work every other weekend. We have a little cabin in Falkenberg where we would like to spend some time ... But we can't, because I don't have time ... I don't have time to do anything at home. (Western Sweden, 2: 1125-1127)

\section{Meaningfulness and appreciation}

The participants found their jobs very meaningful and had ideas of how to improve elderly care. However, they felt a lack of appreciation from the employer.

\subsection{Meaningful job}

Caring for the elderly patients was described as a very meaningful and rewarding part of the job. The participants expressed the sense of satisfaction they got from interacting with the patients.

There is nothing better than to help our elderly, and their gratefulness and their old little hand that pats me ... And they say, 'Oh you make me happy, by being happy.' That is my salary. (Western Sweden, 1: 53-54)

The patients, I mean they give me so much ... There is going to be a feeling of great loss, so I have said that I can stay as a volunteer. (Western Sweden, 2: 869-870) 
The job was not only meaningful and rewarding, but was also something that the participants really enjoyed. Many thought that the job was fun.

It is so much fun working, it is the only fun I have in my life, that is how I feel. (Western Sweden, 4: 336)

Feeling that the work was enjoyable increased the motivation for staying at work.

I feel that I go to work filled with joy, and I think it is fun. So I think I will be able to cope until 65 years. (Southern Sweden, 5: 11-13)

\subsection{Downgrading of competencies}

The employer often failed to value the experience and competence of the assistant nurses, and this was disappointing to the participants.

The staff within elderly care are highly competent in many, many areas, and the employer often fails to realise this. They fail to see all the knowledge that we have gathered during the years, and it is a shame that they can't see that ... and it bothers me. (Western Sweden, 1: 1392-1394)

One example of a situation that was neither noticed nor valued by management was the ability to deal with the many unexpected events that happened during a working day.

Our workplace never closes ... We manage a day in different ways: it never turns out the way you thought in the morning. You do the planning in the morning and then a thousand things happen during the day. But we still manage to handle it because of the competency and knowledge we got ... and who thanks us for this ... nobody. (Western Sweden, 1: 1401-1404)

The participants wanted to contribute to improving elderly care, and the lack of opportunities to do this was very upsetting to some participants.

I get upset, because I really want it to work ... I say, listen to us, how we would like to work, how we can do a good job. How elderly care should be managed. Why don't you listen to us? (Western Sweden, 1: 1154-1156)

\section{Social support}

Support from colleagues appeared to be a very important factor for wellbeing at work. Being part of a group of colleagues created a sense of belonging, and support from colleagues increased the motivation to continue to work.

\subsection{Belonging}

Being part of a social context at work was very important for the wellbeing at work.

The colleagues are the most important part of work. Because if you didn't have them or didn't get along with them, then it would be a catastrophe (short laugh), I think. (Western Sweden, 3: 554-557) 
One participant described how their group of colleagues were always open to discussing any problems that could arise.

A gang that is always there for each other, if you have problem and a crisis in the group you can always sit down together. (Southern Sweden, 5: 308-309)

\subsection{Support from colleagues increases motivation for delaying pension}

Support from colleagues influenced the decision-making process relating to retirement. Having good support meant that it was possible to stay at work even after an age when it was possible to retire.

So my group of colleagues is extremely important for my thinking regarding retirement. Because of them, I can continue to work, and they support me. (Western Sweden, 2: 869-870)

It has been the same staff for a long time and I like them a lot ... and that makes me think that ... otherwise I may have left at 61 years. (Western Sweden, 2: 862-867)

\section{Discussion}

The current study investigated elderly workers' motivation for a full or extended working life. Assistant nurses working in elderly care participated in the study, and five main themes with a number of sub-themes were developed from the interview data. The main themes were 'Organisational issues', 'Health-related problems', 'Private issues', 'Meaningfulness and appreciation' and 'Social support'. Several of the main themes painted an alarming picture of the working conditions of the assistant nurses. For example, the theme 'Organisational issues' highlighted an unsustainable working situation with high demands, lack of staff and lack of recovery. In previous studies, work time and work pace are described as important for the retirement decision (Nilsson 2012, 2016a, 2016b; Sandmark 2014), especially for women (Nilsson 2015). In addition, high demands at work can have both physical and psychological health effects, including an increased risk for depression and anxiety (Andrea et al. 2009) and increased risk of cardiovascular disease (Allesøe et al. 2010). Moreover, a high need for recovery is expected to double the risk of long sick leave two years later (DeCroon, Sluiter and Frings-Dresen 2003) and prospective studies have shown that it is also a valid predictor for cardiovascular diseases and psychosomatic complaints (Sluiter et al. 2003). 'Health-related problems' was a further main theme, and with increasing age, changes in health and in work capacity occur (Kiss, De Meester and Braeckman 2008). Previous studies examining the role of different factors for an extended working life, within health care, found that perceived health was the most important factor in the retirement decision (Bengtsson and Nilsson 2004). Poor physical work environments or badly designed and demanding work conditions leave people worn out; as a result, they retire earlier (Ahola et al. 2012; Nilsson 2012, 2016b; Nilsson, Pinzke and Lundqvist 2010; Nilsson, Rignell-Hydbom and Rylander 2011, 2016; Schuring et al. 2011). The main theme 'Private issues' highlighted the role of economy in the retirement decision, indeed the role of economic incentives in the retirement decision has been 
found in previous studies (Bengtsson and Nilsson 2004). Economic incentives are also used by society to regulate the population's retirement age (Nilsson 2016c). In addition, the participants in the current study clearly expressed that the demanding work situation was having a negative effect on their private life. Previous literature has found that it is important to balance work and private life if individuals want to continue in an extended working life (Nilsson 2016b; Nilsson, Rignell-Hydbom and Rylander 2011), especially for women (Nilsson 2015). Conflict between work and personal life can have negative outcomes, including burnout, depression, low job satisfaction and low psychological wellbeing (Munir et al. 2012). In turn, these outcomes have been related to intention to leave the health-care profession, sickness absence and poor work performance. Work could be an antagonist to leisure activities, and this perceived obstacle is a reason for early retirement (Nilsson 2012, 2016b, 2016c, 2017a, 2017b; Nilsson, Rignell-Hydbom and Rylander 2011). If work interacts with leisure activities and family commitments, retirement may be delayed (Fideler 2014; Mein et al. 1998; Nilsson 2012; Vercruyssen 2003). 'Meaningfulness and appreciation' was a further main theme. This theme highlighted that the job was viewed as very meaningful but that the competencies of the assistant nurses were downgraded. Previous studies with assistant nurses have found that they perceived their jobs as very meaningful (Nilsson and Nilsson 2017a, 2017b; Sandmark 2014). Not surprisingly, meaningful tasks, using experience, knowledge and education in work increase work motivation and work satisfaction (Saurama 2004). In addition, employees close to normative retirement age who experience their work as important and meaningful more often want to go on and work in an extended working life (Nilsson 2012, 2016a, 2017a, 2017b; Nilsson, Rignell-Hydbom and Rylander 2011). Similarly, previous studies have found that employees are more willing to extend their working lives if they can use their existing knowledge at work and have opportunities to gain new knowledge (Nilsson 2012, 2016a, 2016c, 2017a, 2017b; Nilsson and Nilsson; Nilsson, Rignell-Hydbom and Rylander 2011). The final main theme was 'Social support'. Previous research shows that support from managers, work colleagues and being included in a social group at the workplace plays an important role in wellbeing among staff (Nilsson 2012, 2016a, 2017a, 2017b; Nilsson and Nilsson 2017a; Nilsson, Rignell-Hydbom and Rylander 2011). Social relationships at work have also been found to play a part in the decision on when to retire (Bengtsson and Nilsson 2004; Nilsson 2012, 2016a, 2017a; Nilsson, Rignell-Hydbom and Rylander 2011).

This study found five themes in relation to retirement for assistant nurses. Those themes were related to the nine areas earlier evaluated in quantitative crosssectional studies and review studies (Nilsson 2006, 2016c; Nilsson, RignellHydbom and Rylander 2011) and in the theoretical model for a sustainable working life for all ages (Nilsson 2016d; swAge 2016). In the model it is proposed that, whether workers can and want to extend working life depends on the nine areas: health, physical work environment, mental/psycho-social work environment, working time and work pace, knowledge and competence, work motivation and work satisfaction, the attitude of managers and the organisation/enterprise towards older workers, the family situation and leisure activities (Nilsson 2006, 2012, 2016a, 2016b, 2017b; Nilsson, Rignell-Hydbom and Rylander 2011). The worker's decision 
to extend working life relies on these four considerations: (a) their health and wellbeing in relation to (i) their physical and mental work environment, (ii) their working time and workload, and (iii) their opportunity to recovery from work; (b) their personal finances; (c) whether their possibility for social inclusion in a group is best realised inside or outside working life; and (d) whether their possibility for a selfcrediting and motivating occupation is best realised inside or outside working life (Nilsson 2012, 2016a, 2016b). The coherence between the results of the current study's independent analysis and the theoretical model provides a reliability that gives a robustness to the results in this study, as well as strengthening the robustness of the theoretical model for a sustainable working life for all ages (swAge 2016).

\section{Limitations and implications}

Regarding limitations, it may be that the participants found it hard to disagree with others in the group. However, in non-natural focus groups the participants do not have to place much focus on caring about a good relationship in the future. Regarding the transferability of the findings, it could be said that the themes are relevant to many other assistant nurses in similar workplaces. For the current study, it is also important to relate the findings to previous research (see above) and thereby add to the accumulation of results regarding elderly workers' motivation for retirement or an extended working life (Willig 2013).

The implications of these findings, based on the assistant nurses' own words, are that the working conditions of assistant nurses at care homes for elderly patients need to be improved to create a more sustainable working life. Decreasing the work demands appears to be one of the most important steps. This could be done in several different ways, e.g. by increasing the number of staff and, because work was experienced as physically demanding, by creating less heavy work tasks for elderly employees. There is also a need for assistant nurses to have recovery opportunities during work and to have sufficient recovery time from work between shifts. The balance between private life and work life could thereby also be improved. A better work-life balance could be an important step in creating a sustainable work life for assistant nurses, as many liked their jobs but felt that they lacked a private life. They wanted more time for family, friends and leisure activities. Another suggestion from the results is to use the expertise and experience of the older employees to a greater extent, e.g. in supervisory/mentor roles for younger members of staff. This has also been suggested in a recent qualitative study investigating successful participation in working life after retirement age (Wentz and Gyllensten 2016). Assistant nurses having better opportunities to use their knowledge and experience would seem to be a win-win situation for both the organisation and the assistant nurses. Moreover, upgrading the competency and professionalism of the assistant nurse could help to increase the motivation for a full or extended working life. What is lacking from the results is human agency and a sense of empowerment or control over the work situation. This is in contrast to previous studies that have demonstrated that employees exercise agency at work and behave proactively (Kooij, Tims and Kanfer 2015). Several researchers have shown that older workers use action-regulation strategies aimed at changing their environment to adapt to age-related changes (e.g. Wahl, Iwarsson and Oswald 
2011). Thus, one implication of the results is the suggestion to increase job control and create a sense of empowerment over the work situation for assistant nurses.

\section{Conclusion}

The present study explored older workers' motivation for a full or extended working life. The results showed that the assistant nurses faced several difficulties including high demands, health-related problems, lack of private life and downgrading from the organisation. On the other hand, the work was experienced as highly meaningful and socially rewarding. These factors have been previously identified in a theoretical model for a sustainable working life for all ages. Increasing the number of staff and improving recovery opportunities and work-life balance could be important steps to improving the working conditions for this group. Finally, upgrading the competency and professionalism of assistant nurses could help to increase the motivation for a full or extended working life.

\section{Note}

1 The interview number and line numbers from the transcript are presented after each quote.

Acknowledgements. The authors would like to thank all the participants for their time, co-operation and involvement in this study.

Author contributions. All authors have made a substantial contribution to the conception and design, or analysis and interpretation of data, and the drafting or revising of the article.

Financial support. This study was funded by Forte (2012-1696).

Conflict of interest. There are no conflicts of interests.

Ethical standards. The study has been approved by the Regional Ethical Board in Gothenburg (dnr. 646-15) and by the Regional Ethical Board in Lund (dnr. 2013:722).

\section{References}

Ahola K, Sirén I, Kivimäki M, Ripatti S, Aromaa A, Lönnqvist J and Hovatta I (2012) Work-related exhaustion and telomere length: a population-based study. PLOS ONE 7, e40186.

Allesøe K, Hundrup YA, Thomsen JF and Osler M (2010) Psychosocial work environment and risk of ischaemic heart disease in women: the Danish Nurse Cohort Study. Occupational and Environmental Medicine 67, 318-322.

Andrea H, Bültmann U, van Amelsvoort LG and Kant Y (2009) The incidence of anxiety and depression among employees: the role of psychosocial work characteristics. Depression and Anxiety 26, 1040-1048.

Aronsson G, Astvik W and Gustafsson K (2013) Work conditions, recovery and health: a study among workers within pre-school, home care and social work. British Journal of Social Work 44, 1654-1672.

Bengtsson E and Nilsson K (2004) Äldre medarbetare. En kvalitativ studie om medarbetares villkor $i$ arbetslivet inom hälso-och sjukvården [Older workers. A qualitative study regarding working conditions within health-care]. Lund, Sweden: Hellmans förlag/Sociologiska institutionen, Lunds universitet.

Braun V and Clarke V (2006) Using thematic analysis in psychology. Qualitative Research in Psychology 3, 77-101.

DeCroon EM, Sluiter JK and Frings-Dresen MH (2003) Need for recovery after work predicts sickness absence: a 2-year prospective cohort study in truck drivers. Journal of Psychosomatic Research 55, 331-339. 
Elstad JI and Vabø M (2008) Job stress, sickness absence and sickness presenteeism in Nordic elderly care. Scandinavian Journal of Public Health 36, 467-474.

European Commission (2012) Citizen's Summary - White Paper on Pensions: EU Proposals Explained. Brussels: European Commission.

Fideler EF (2014) Men Still at Work: Professionals Over Sixty and on the Job. Plymouth, UK: Rowman and Littlefield.

Kiss P, De Meester M and Braeckman L (2008) Differences between younger and older workers in the need for recovery after work. International Archives of Occupational and Environmental Health 81, 311-320.

Kitzinger J (1995) Qualitative research: introducing focus groups. BMJ: British Medical Journal 311, 299.

Kooij DTAM, Tims M and Kanfer R (2015) Successful aging at work: the role of job crafting. In Bal P, Kooij D and Rousseau D (eds), Aging Workers and the Employee-Employer Relationship. New York: Springer, pp. 145-161.

Lain D and Vickerstaff S (2014) Working beyond retirement age: lessons for policy. In Harber S and Hamblin K (eds), International Handbook on Ageing and Public Policy. Cheltenham, UK: Edward Elgar, pp. 242-255.

Mein G, Higgs P, Ferrie J and Stansfeld SA (1998) Paradigms of retirement: the importance of health and ageing in the Whitehall II Study. Social Science and Medicine 47, 535-545.

Munir F, Nielsen K, Garde AH, Albertsen K and Carneiro IG (2012) Mediating the effects of work-life conflict between transformational leadership and health-care workers' job satisfaction and psychological wellbeing. Journal of Nursing Management 20, 512-521.

Nilsson E and Nilsson K (2017a) Time for caring? Elderly care employees' occupational activities in the cross draft between their work priorities, 'must-do's' and meaningfulness. International Journal of Care Coordination 20, 8-16.

Nilsson E and Nilsson K (2017b) The transfer of knowledge between younger and older employees in the health and medical care: an intervention study. Open Journal of Social Sciences 5, 71-96.

Nilsson K (2006) Äldre medarbetares attityder till ett långt arbetsliv. Skillnader mellan olika yrkesgrupper inom hälso- och sjukvården [Older workers' attitudes to an extended working life: differences between occupations in health and medical care]. Arbetsliv $i$ omvandling 10, 1-69.

Nilsson K (2012) Why work beyond 65? Discourse on the decision to continue working or retire early. Nordic Journal of Working Life Studies 2, 7-28.

Nilsson K (2015) Kön och ålderspension - en tvärsnittstudie om skillnader mellan män och kvinnor $i$ att kunna och vilja arbeta till 65 år eller längre [Gender and old-age pension: a cross-sectional study of the differences between men's and women's ability and willingness to work to 65 years or longer.] Lund, Sweden: Lund University.

Nilsson K (2016a) Conceptualisation of ageing in relation to factors of importance for extending working life: a review. Scandinavian Journal of Public Health 44, 490-505.

Nilsson K (2016b) Interventions to reduce injuries among older workers: a review of evaluated intervention projects. Work: A Journal of Prevention, Assessment, and Rehabilitation 17, 471-480.

Nilsson K (2016c) The ability and desire to extend working life. In Vingård E (ed.), Healthy Workplaces for Men and Women in All Ages. Knowledge Compilation 2016:8. Stockholm: Arbetsmiljöverket, pp. 31-49.

Nilsson K (2016d) swAge Model: Sustainable Working Life for All Ages. Available online at http://www. swage.org/ (accessed 24 April 2017).

Nilsson K (2017a) Active and healthy ageing at work. A qualitative study with employees 55-63 years and their managers. Open Journal of Social Sciences 5, 13-29.

Nilsson K (2017b) The influence of work environmental and motivation factors on seniors' attitudes to an extended working life or to retire. A cross sectional study with employees 55-74 years of age. Open Journal of Social Sciences 5, 30-41.

Nilsson K (2017c) Bäst före datum på arbetskraften? - olika åldersbegrepps betydelse för äldre i arbetslivet [Best before date on the workforce? Different age concepts important for older people in the workplace]. In Krekula C and Johansson B (eds), Introduktion till kritiska åldersstudier. Lund, Sweden: Studentlitteratur, pp. 169-182.

Nilsson K (2017d) Managers' attitudes to their older employees: a cross-sectional study. Work: A Journal of Prevention, Assessment, and Rehabilitation 59, 49-58. 
Nilsson K, Östergren P-O, Kadefors R and Albin M (2016) Has the participation of older employees in the workforce increased? Study of the total Swedish population regarding exit from working life. Scandinavian Journal of Public Health 44, 506-516.

Nilsson K, Pinzke S and Lundqvist P (2010) Occupational injuries to senior farmers in Sweden. Journal of Agricultural Safety and Health 16, 19-29.

Nilsson K, Rignell-Hydbom A and Rylander L (2011) Factors influencing the decision to extend working life or retire. Scandinavian Journal of Work, Environment and Health 37, 473-480.

Nilsson K, Rignell-Hydbom A and Rylander L (2016) How are self-rated health and diagnosed disease related to early or deferred retirement? A cross-sectional study of employees aged 55-64. BMC Public Health 16, 886.

Noelker LS, Ejaz FK, Menne HL and Jones JA (2006) The impact of stress and support on nursing assistant satisfaction with supervision. Journal of Applied Gerontology 25, 307-323.

Organisation for Economic Co-operation and Development (2007) Population Pyramids in 2000 and 2050. OECD Statistics Portal: Demography and Population. Available online at http://stats.oecd.org (accessed 24 April 2017).

Round A (2017) Extending Working Lives. Institute for Public Policy Research. Available online at www. ippr.org/north (accessed 24 April 2017).

Sandmark H (2014) Orka jobba till 65? Stockholm: Gothia Fortfbildning.

Saurama L (2004) Experience of Early Exit. A Comparative Study of the Reasons for and Consequences of Early Retirement in Finland and Denmark in 1999-2000. Helsinki: Finnish Centre for Pension Studies.

Schuring M, Mackenbach J, Voorham T and Burdorf A (2011) The effect of re-employment on perceived health. Journal of Epidemiology and Community Health 65, 639-644.

Sluiter J, De Croon E, Meijman T and Frings-Dresen M (2003) Need for recovery from work related fatigue and its role in the development and prediction of subjective health complaints. Occupational and Environmental Medicine 60, 62-70.

swAge (2016) The swAge Model: Theoretical Model for Sustainable Working Life for all Ages. Available online at http://www.swage.org/ (Accessed 15 April 2017).

Vercruyssen M (2003) Lifespan functional fitness: encouraging human struggle (physical activity) and warning about the cost of technology. In Kumashiro M (ed.), Aging and Work. London: Taylor \& Francis, pp. 62-71.

Wahl H, Iwarsson S and Oswald F (2011) Aging well and the environment: toward an integrative model and research agenda for the future. The Gerontologist 52, 306-316.

Wentz K and Gyllensten K (2016) Career crafting: working during the ages of 69-75 years. Journal of Business and Economics 7, 1334-1345.

Willig C (2013) Introducing Qualitative Research in Psychology. London: McGraw-Hill Education.

Woodhead EL, Northrop L and Edelstein B (2016) Stress, social support, and burnout among long-term care nursing staff. Journal of Applied Gerontology 35, 84-105.

Cite this article: Gyllensten K, Wentz K, Håkansson C, Hagberg M, Nilsson K (2019). Older assistant nurses' motivation for a full or extended working life. Ageing \& Society 39, 2699-2713. https://doi.org/ $10.1017 /$ S0144686X18000740 